This item was submitted to Loughborough's Research Repository by the author.

Items in Figshare are protected by copyright, with all rights reserved, unless otherwise indicated.

\title{
Milling a cement-based 3D printable mortar in its green state using a ball- nosed cutter
}

PLEASE CITE THE PUBLISHED VERSION

https://doi.org/10.1016/j.cemconcomp.2021.104266

PUBLISHER

Elsevier

VERSION

AM (Accepted Manuscript)

PUBLISHER STATEMENT

This paper was accepted for publication in the journal Cement and Concrete Composites and the definitive published version is available at https://doi.org/10.1016/j.cemconcomp.2021.104266

LICENCE

CC BY-NC-ND 4.0

\section{REPOSITORY RECORD}

Dobrzanski, James, Richard Buswell, Sergio Pialarissi-Cavalaro, Peter Kinnell, Weiqiang Wang, Jerry Xu, and John Kolawole. 2021. "Milling a Cement-based 3D Printable Mortar in Its Green State Using a Ball-nosed Cutter". Loughborough University. https://hdl.handle.net/2134/16930702.v1. 


\title{
1 Milling a cement-based 3D printable mortar in its green 2 state using a ball-nosed cutter
}

3

4

5

6

7

8

9

\begin{abstract}
A key benefit of 3D concrete printing is the removal of the need for a mould enabling one-off and low volume production with greater variability in part geometry. The staircase effect generated by the layering is used as a feature of many applications, however for smooth surfaces and at interfaces between components, this may not always be desirable. In addition, global deformation of the part during printing may influence the accuracy of the final element. In order to compete with cast equivalents in this regard, secondary treatments such as subtractive milling and trowelling can be applied post printing. These are relatively new developments in the field of digital fabrication with concrete and there is little published work on methods and in particular, none that examine the effect of milling on the surface condition of 3D printing mortar. This paper explores these issues based on a manufacturing tooling perspective and finds that high quality surfaces can be formed, the roughness of which is affected by the size of the aggregates in the mix and the set-state of the material, which needs to be close to the solid state. In practice, this results in a 'milling window' which has implications for process timing and the robotic systems typically deployed for 3D concrete printing applications.
\end{abstract}

\section{Introduction}

Large-scale additive manufacturing, commonly referred to as 3D Concrete Printing (3DCP) has, alongside many other novel digital fabrication methods, emerged worldwide in response to the global call to modernise construction manufacturing [1-3]. There has been a proliferation of methods stemming from the early work in the 2000's $[4,5]$ to the richer variety of process and applications found in the contemporary field [6-9]. Demonstrated methods fall broadly into two categories: onsite house building and off-site manufacturing [10] and in the UK, additive manufacturing of buildings has been recognised as a Modern Method of Construction [1].

Digitally driven processes offer benefits of productivity [11] and additive manufacturing enables a significant amount of variability in design geometry with no increase of fabrication costs [12]. The potential for manufacture in architecture, construction and infrastructure is significant as traditionally component differences are engineered out to enable cost effective manufacture: often this is the reuse of moulds to cast concrete [13-16]. The effort in conventional casting is in the preparation of the mould, where the shape is determined within predefined tolerances, surface finish and detail by the mould material and its preparation [17]. The degree of quality and complexity affects the cost and hence concrete components tend to be prismatic volumes that use more material than necessary to perform structurally. One criticism of this approach is the amount of redundant material used, increasing the service weight of the component and resource use. There are new approaches in mould manufacture/forming that address this issue [18-21]. 
The alternative offered by 3DCP offers greater part-to-part variation in geometry, but this is traded off against the achievable precision, affected principally by two factors: deformation of the wet material during manufacture [22-25] and the staircase effect generated by the layering of material that effects all additive manufacturing processes [26-28]. Recent international collaborative work has created a process classification framework for Digital Fabrication with Concrete (DFC) [10], and through this lens it becomes apparent that conventional casting and 3DCP are single material shaping methods: the former is a formative process; and the latter additive. This single step approach in production limits the achievable surface finish and shape complexity and the achievable dimensional precision and accuracy. Subtractive shaping processes are capable of higher precision that additive methods and is well practiced on metals, wood, plastics and ceramics. Milling hard materials used in civil and construction engineering have also been explored: in stone [29]; concrete [30,31] and for applications including heritage conservation [32].

The highly abrasive nature of concrete can cause significant tool wear [33]. The resistance offered by the material leads to high cutting forces and tend to require very stiff and heavy machines. Robotic arms typically used for positioning in 3DCP applications are comparatively flexible, hence more suited to smaller cutting forces compatible with green concrete. Taking advantage of the plastic-solid transition of concrete to enable the use of additive and subtractive process tools on a single lighterweight robot is, therefore, commercially advantageous.

Such hybrid approaches have been shown to yield benefit, particularly in low volume production for architectural elements [34]. Lindemann et al. [35] and Kloft et al. [36] used a rotating smoothing disk to improve the surface condition and a milling tool to trim edges of a double-curved panel manufactured using a Jetting-based, additive manufacturing process. Bard et al. [37] applied automated trowelling methods to an extrusion-based, additive manufacturing process to achieve high finish quality while creating variable surface textures and an EU funded project has also demonstrated surface treatments and drilling in combination with extrusion based 3DCP[38].

However, to the best knowledge of the authors there are currently no published research articles that examine the interaction of milling tools a 3DCP printing mortars when in the green state. This paper offers an exploratory investigation in this developing area of interest by applying a versatile ball-nose cutting tool to mill the surface of printing mortar with a maximum aggregate size of $2 \mathrm{~mm}$. Machining trials are carried out over various stages of the material's green state, using a range of feed traverse speeds and spindle speed rates. The effects of milling on the surface quality are explored using a highresolution optical imaging method and the dependencies of surface quality on the curing time and the tool feed and speed rates derived.

\section{Background: Milling}

Milling is a shear-based material removal process where a cutting surface, on a rotating tool, is used to mechanically remove material from a workpiece by means of a shearing action. There are many types cutting tool with differing geometry. The cutting tool geometry results in differing capabilities and characteristics, such as rate of material removal and profile of the resulting surface, width and depth of cut and quality of finish. Milling is particularly well suited where a high quality of surface finish is required: frequently in the machining of metallic materials, the desired finish can be achieved in a single pass of a cutter across a surface. Figure 1a depicts three configurations of a ball-nose end mill tool applied to milling horizontal and vertical surfaces. 


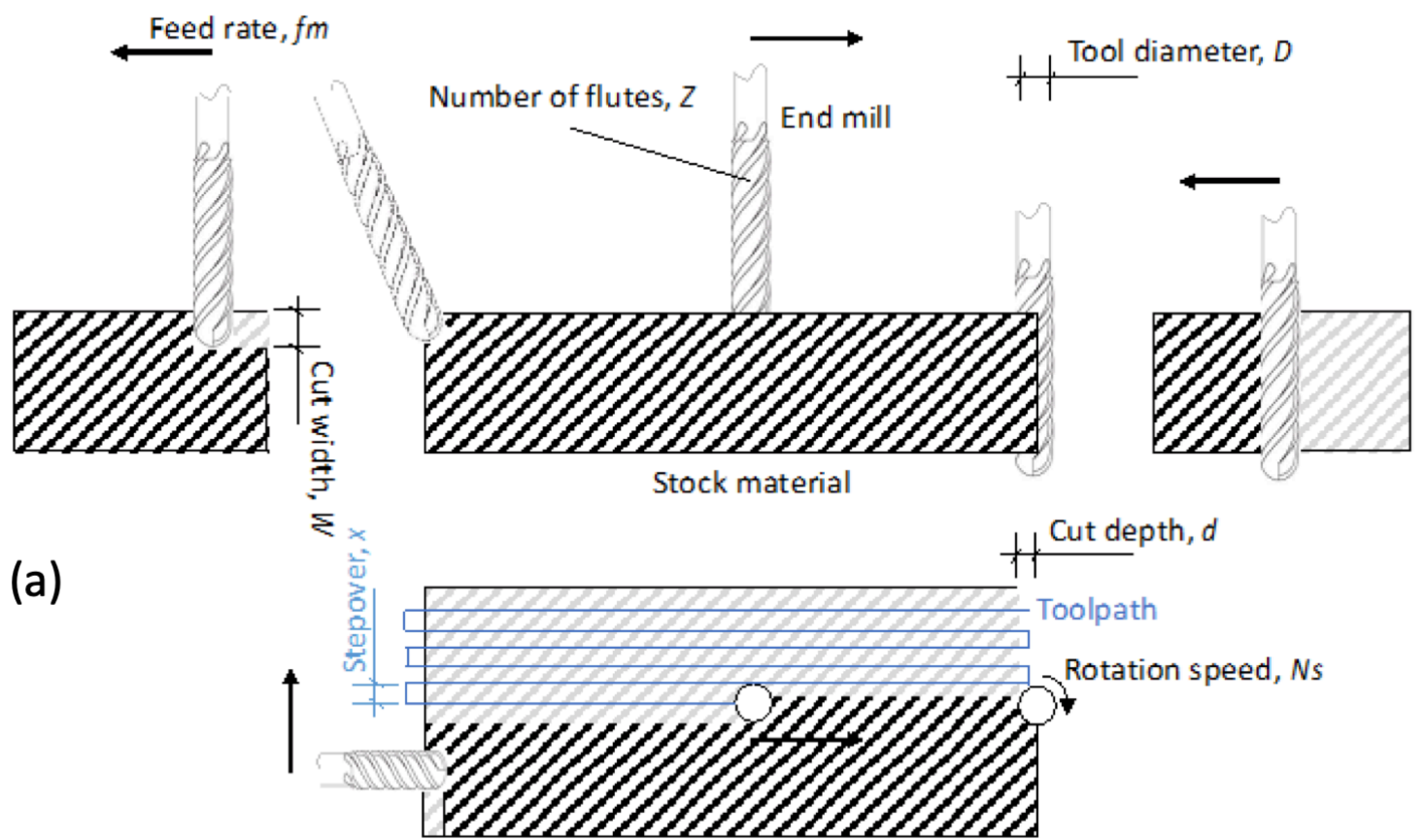

(b)

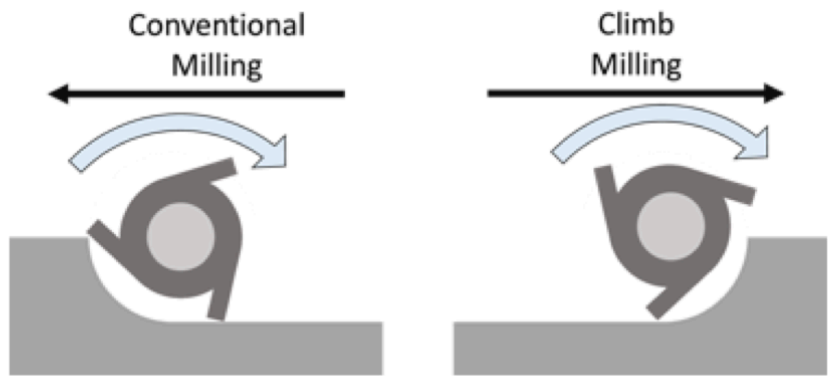

87

Figure 1: (a) typical milling tool positions for horizontal and vertical surface milling and (b) conventional (left) and climb milling (right).

The milling tool can also be moved in one of two directions in relation to the feedstock (printed material), depicted in Figure $1 \mathrm{~b}$. Conventional milling is the preferred choice of cutting for harder metals and has the advantage of pushing against the backlash of a milling machines lead screws. Climb milling evacuates the materials behind the cuts taken achieving better surface finish, although typically used for taking finer cuts than conventional milling.

The milling operation undertaken in this study uses a ball-nose end mill where the cutting action can take place across the whole surface of the tool. This is a versatile option because the end-mill can be used to cut horizontal surfaces using the end of the tool, vertical surfaces using the end, or side of the tool and can be used for drilling. The surface finish achieved is influenced by the tool path and tool operation which includes parameters such as: the stepover, $x(\mathrm{~mm})$, rotational speed of the spindle $N_{S}$ (rev/min), tool diameter, $D(\mathrm{~mm})$, cut depth, $d,(\mathrm{~mm})$ and cut width, $W(\mathrm{~mm})$. These parameters also dictate the cutting speed of the tool, $V(\mathrm{~mm} / \mathrm{s})$, where, $V=\pi D N_{s}$, and the feed rate of the material onto the tool, $f_{m}(\mathrm{~mm} / \mathrm{s})$, is given by $f_{m}=N_{s} f_{z} Z$, where $f_{Z}$ is the distance the material is fed 
onto the tool per tooth and the number of teeth is equal to the number of flutes $Z$. Note that in the application here, the material is stationary and the tool on moved.

In order to effectively mill the mortar in this study in its plastic-solid state, the timing of the processing must ensure that the material is stiff enough to retain its form after printing or casting and that it is hard enough to be machined effectively, creating chips of material that are removed under shearing during the cutting process. The resultant surface must then, of course be of appropriate quality.

From the foregoing it is hopefully evident that the cured state of the material, the depth, width of cut, cutting speed and tool type are all critical factors in determining the accuracy and precision of the achievable surface finish in homogeneous materials. Mortars and concretes are composite material comprising of a range of aggregate sizes, which will also play a role in determining the surface quality post milling. The work reported here focuses on a subset of these variables.

\subsection{Context for the investigation}

Milling can be applied for the treatment of surfaces and the creation of more defined edges and details. This work was informed by trials to manufacture a demonstration part, with features that cannot be reproduced using 3DCP and with detail that would be costly to manufacture using conventional moulding techniques.

A ribbed panel component was designed and manufactured using the hybrid approach. Figure 2 depicts the printed 'near-net shape' component on the left, and on the right, the net-shaped part after post-processing with the milling tool. The approach requires two sets of toolpaths, one for the printing operations and one for the milling applied when the material is close to its solid state. The trial demonstrated the feasibility of the approach and lead to a more detailed investigation of the condition of the resultant milled surface, reported here.
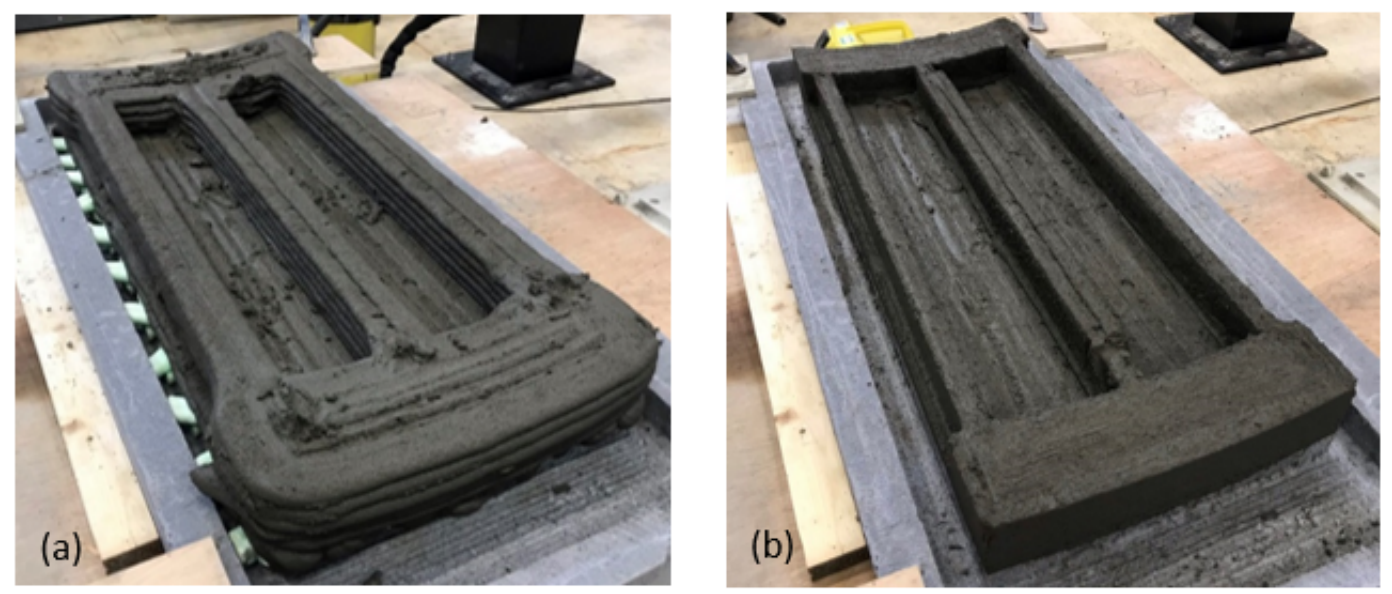

Figure 2: A 3DCP printed part (a), the part post processed to achieve the net shape (b).

\section{Materials and method}


Materials typically used in milling are homogeneous but cement-based mortars are composite materials with time dependent properties that vary at a significant rate during the initial period after hydration commences. There are no precedents on which to base this investigation and the

From the initial trials commissioning and setting up the equipment in order to manufacture the part depicted in Figure 2, there are a number of factors that influence the successful milling of a 3D printed part while in its plastic-solid state, which are primarily the material state and the tooling parameters, however, the ability of the part to resist the forces applied by the milling tool will practically limit the size of the feature that can be treated.

To minimise the influence of such factors and any influence of excess material that can collect on the surface, repeatable control was sought in order to create consistency between samples and so placing the printing mortar in moulds prior to milling would constrain the variability of the material positioning, ensuring repeatable, flat and even surfaces through which the tool could pierce so the cut surface could be examined.

\subsection{Comparing printed and cast material}

In order to understand the extent to which the cast material compares to the printed material, a single batch of the standard 3DCP blend used at Loughborough University was used to print and cast one sample of each at a similar scale to the intended experimental samples. Both were cured and then cut using the same diamond saw and then inspected using optical measurement (described in Section 3.6) and the data obtained was post processed in the MountainsMap software to evaluate the number and sizes of pores with a perimeter greater than $15 \mathrm{um}$. Figure 3a presents an image of the cut surface of the cast material, and Figure $3 b$ the printed. Figure $3 c$ and $d$ present a higher magnification of the of a smaller portion of the cut surface.

Both samples were fully dense and did not exhibit any of the defects between layers or between filaments as reported in $[39,40]$. A larger number of pores were identified in the printed material (203 vs 124), which were of a smaller size than in cast specimens $\left(0.037 \mathrm{~mm}^{2}\right.$ vs $\left.0.120 \mathrm{~mm}^{2}\right)$, however the distribution across the inspected area was similar.

The influence of such variations in the milling results reported here should be negligible as the milling head penetrates several millimetres into the cross-section, albeit not enough to surpass the first bead layer closer to the surface. Moreover, the aggregate should have a significantly larger influence than the porosity on the milling process and surface finish quality due to the larger size (maximum of $2 \mathrm{~mm}$ ). The similar aggregate distribution found in cast and 3D printed samples (Figure $3 c$ and d) further supports the comparable nature of printed and cast samples used here. 

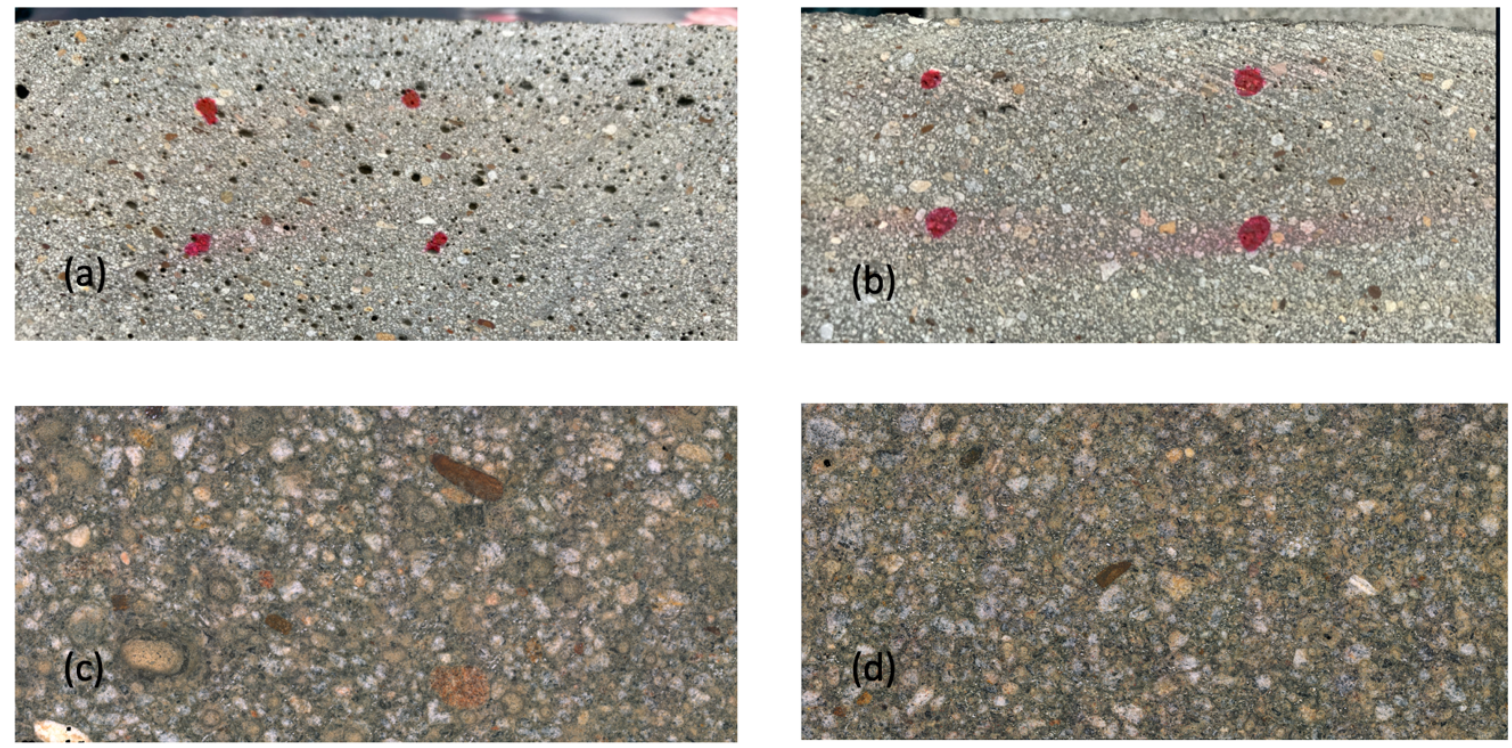

Figure 3: the cut surfaces of the cast sample (a) and the printed sample (b) and a magnified view of a the surface (c) cast and (d) printed.

\subsection{Experimental design overview}

The experimental programme explores the influence of the milling process and mortar-related variables on the horizontal surface characteristics of mortar specimens. The process variables selected for exploration were the spindle speed and the feed rate of the material onto the tool, based on the significance of their influence on surface quality when milling other materials. The speed and feed rates investigated here were 1000, 1500 and $2000 \mathrm{rpm}$ and 15, 30, 45 and $90 \mathrm{~mm} / \mathrm{s}$ respectively.

The material variable investigated was the stiffness in its plastic state during milling: before initial setting time, between initial and final setting and immediately after the final setting time. The state of the material is likely to affect the way in which the material is cut with the milling tool, potentially leading to chip formation and the presence of cutting debris on the surface after cutting. It will also influence tool wear and the energy required to carry out the operations.

A Vicat test was used to characterise the setting rate in order to a identify three time-windows in which to evaluate surface quality due to milling: one before the onset of setting, one mid-way through setting and one just as the material is hardening. A patch of each cast beam was milled on the top horizontal surface with a predetermined toolpath configuration at these times to leave three or four milled sample areas on each beam representing the curing states. Each beam represented a combination of tool rotational speed and cutting speed.

These surfaces were then examined using high resolution surface metrology equipment to both explore the surface condition and to quantify the surface roughness using standard manufacturing metrics, that could then be used to investigate the dependencies of the surface quality on each of the three parameters: material stiffness, tool speed and cutting speed. Details on each stage follow.

\subsection{Mortar composition, mixing and production of cast specimens}


The mortar mix used was taken from [41,42] and was produced in $40 \mathrm{I}$ batches having the composition shown in Table 1. All solid components were introduced in a Hobart $\mathrm{H}$ series mixer with nominal capacity $60 \mathrm{I}$ and mixed for 5 minutes at speed $350 \mathrm{rpm}$. Then, $80 \%$ of the water was added and mixed for 5 minutes more. Finally, the remaining water and the whole content of superplasticiser were added and mixed for 5 minutes.

Table 1: Material Composition (in Kg)

\begin{tabular}{|c|c|c|c|c|c|}
\hline Cement & $\begin{array}{c}\text { silica } \\
\text { fume }\end{array}$ & fly ash & $\begin{array}{c}\text { natural } \\
\text { river fine } \\
\text { sand }\end{array}$ & $\begin{array}{c}\text { BASF } \\
\text { Master } \\
\text { Glenium 51 }\end{array}$ & Water \\
\hline 42.5 & 3.32 & 3.64 & 49.7 & 0.607142857 & 15.45455 \\
\hline
\end{tabular}

Immediately after mixing approximately $400 \mathrm{ml}$ of fresh mortar was sampled for the Vicat test, and the remaining mortar was used to cast two types of prismatic metallic moulds with internal dimensions $20 \times 100 \times 600 \mathrm{~mm}$ and $20 \times 100 \times 450 \mathrm{~mm}$. A total of three moulds were filled per type and batch and vibrated over a vibrating table for 120 seconds. The surface of the mortar not in contact with the moulds was hand floated using an edge trowel to ensure access material was consistent across all samples.

Figure 4 shows the moulds filled in each batch. Damp Hessian and plastic was placed over the moulds to limit water evaporation from the surface of the specimen exposed to the environment. This was only removed shortly before the start of the milling process.

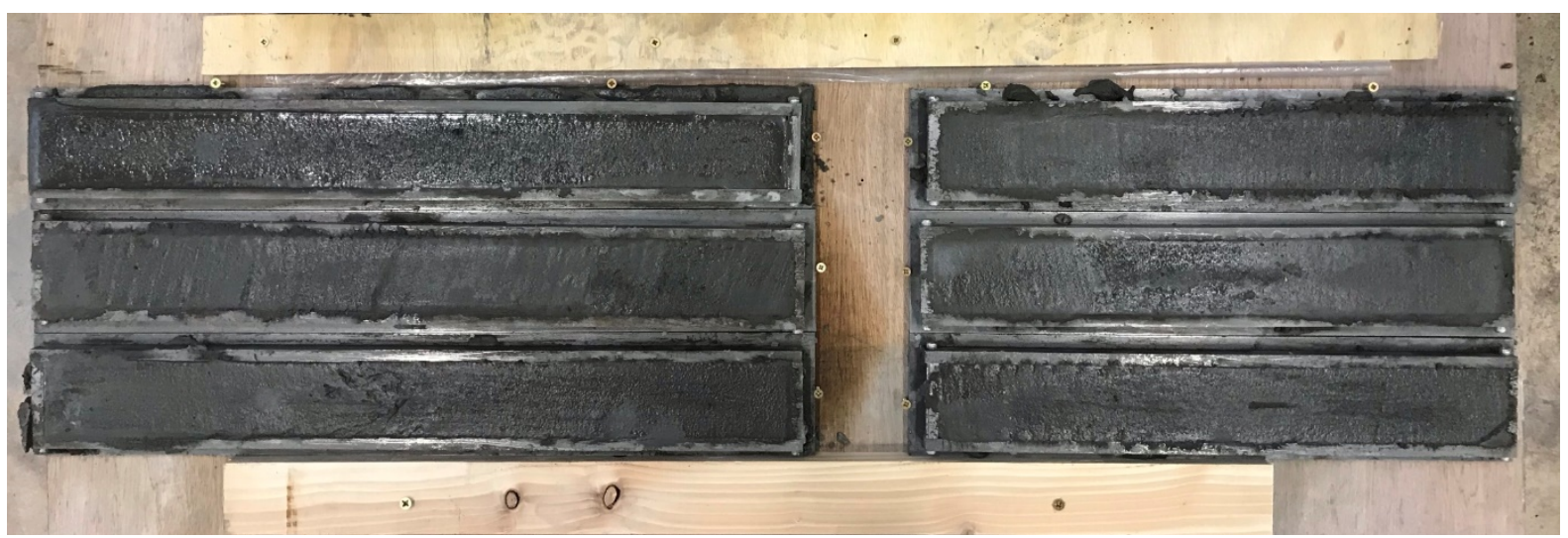

Figure 4: Set of specimens produced per batch prior to curing damp hessian and plastic is used to prevent evaporation of water from the surface.

Three batches were produced on different days to assess the influence of the state of the mortar at the moment of milling: one before setting begins, one after setting ends and one between setting start and end. The moment of milling was defined for each batch independently based on the result of the corresponding Vicat test results. This procedure assumes that the evolution of setting in the Vicat sample approximates that of cast prisms, enabling the correct definition of the moment of milling in relation to the mortar setting process. This is a reasonable assumption since the thermohygrometric conditions of all specimens are similar and their smallest dimension is within the same order of magnitude. All times indicated hereinafter refer to the end of the mixing process.

\subsection{Milling setup and procedure}


The milling was performed in an ABB IRB 6640 robot that had a spindle motor attached to the end of the robotic arm. The milling end tool chosen was a non-coated ball nose flute cutter with a diameter of $16 \mathrm{~mm}$. This type of cutter has been successfully and steadily used in previous trials (Figure 2) and a brand-new one was used in this milling operation to avoid any influences related to uncertain tool defects.

The toolpaths were virtually pre-programmed per batch specimens. The two sets of specimens out of different moulds from one batch were defined with milling regions measuring $70 \times 40 \mathrm{~mm}$ over their exposed top surface as depicted in Figure 5 . In each milling region, milling was planned in a clockwise spiral direction following inside-out contour offset paths, with $2.66 \mathrm{~mm}$ cut depth and $5 \mathrm{~mm}$ toolpath stepover.

The feed rate and the cutting speed were respectively evaluated in these regions of the two sets of specimens. Three repetitions were made per combination of variables. These process-related variables were defined based on trials conducted in the context of previous experimental programmes and presented in Table 2.

For tests on the influence of axial depth and radial depth as well as conventional and climb milling a further set of experiments were undertaken. For these tests a proportion of the mill was used. During the axial cut experiments the plunge depth of the cut using the mill was varied then the surface measured to determine how this coupled with the curing state of the material affected the roughness of the finished surface. Climb and conventional milling was tested using the flutes of the mill to prep the sides of the test piece. Both climb and conventional milling were used to determine if the rotational direction of the mill has a greater or lesser effect on the surface finish of the material. As with the axial cut tests the depth of the radial cuts was varied and these sets of experiments are 

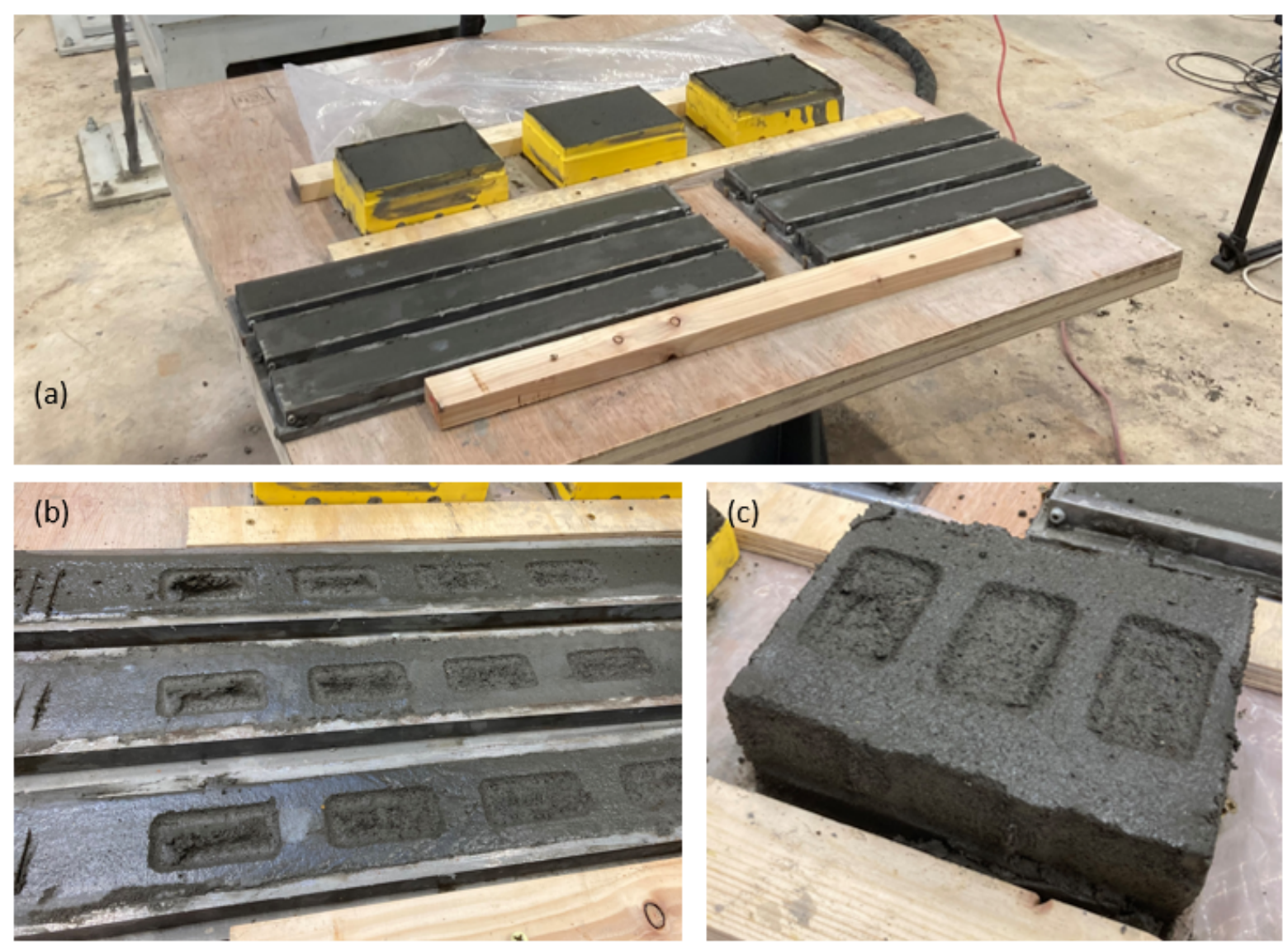

Figure 5: Prepared specimens for the milling testing 5a, with the speed and feed sets shown in figure $5 b$ and the axial/radial sets shown in Figure $5 c$.

Table 2: Milling process related variables setup for one batch specimens.

\begin{tabular}{|c|c|c|c|c|c|c|c|c|c|c|c|c|c|}
\hline Set & \multicolumn{10}{|c|}{1} & \multicolumn{3}{|c|}{2} \\
\hline Specimen & \multicolumn{3}{|c|}{1} & \multicolumn{4}{|c|}{2} & \multicolumn{3}{|c|}{3} & 4 & 5 & 6 \\
\hline Region & \begin{tabular}{|l|l|}
$1 \_1$ & $1 \_2$ \\
\end{tabular} & 1_3 & 1_4 & $2 \_1$ & $2 \_2$ & 23 & $2 \_4$ & $3 \_13 \_2$ & 3 & 3_4 & \begin{tabular}{|l|l|l|}
$4 \_1$ & $4 \_2$ & $4 \_3$ \\
\end{tabular} & \begin{tabular}{|l|ll|l|}
$5 \_1$ & $5 \_2$ & $5 \_3$ \\
\end{tabular} & \begin{tabular}{|l|l|l|l}
$6 \_1$ & $6 \_2$ & $6 \_3$ \\
\end{tabular} \\
\hline feed rate $[\mathrm{mm} / \mathrm{s}]$ & \begin{tabular}{|l|l|}
15 & 30 \\
\end{tabular} & 45 & 90 & 15 & 30 & 45 & 90 & \begin{tabular}{|l|l|}
15 & 30 \\
\end{tabular} & 45 & 90 & & 30 & \\
\hline Spindle speed [rpm] & \multicolumn{10}{|c|}{1500} & 1000 & 1500 & 2000 \\
\hline Cut depth [mm] & \multicolumn{13}{|c|}{2.66} \\
\hline Milling direction & \multicolumn{13}{|c|}{ Clockwise spiral } \\
\hline Toolpath stepover [mm] & \multicolumn{13}{|c|}{5} \\
\hline
\end{tabular}

Table 3: Milling process during axial and radial cut experiments.

\begin{tabular}{|c|c|c|c|c|c|c|}
\hline Set & \multicolumn{3}{|c|}{ Axial Cuts } & \multicolumn{3}{|c|}{ Climb and Conventional Cuts } \\
\hline Specimen & 1 & 2 & 3 & 4 & 5 & 6 \\
\hline feed rate $[\mathrm{mm} / \mathrm{s}]$ & \multicolumn{6}{|c|}{30} \\
\hline Spindle speed [rpm] & \multicolumn{6}{|c|}{1500} \\
\hline Cut depth $[\mathrm{mm}]$ & \multicolumn{6}{|c|}{$2.66,4,8$} \\
\hline Milling direction & \multicolumn{3}{|c|}{ Clockwise spiral } & \multicolumn{3}{|c|}{ Climb and conventional } \\
\hline Toolpath stepover [mm] & \multicolumn{6}{|c|}{5} \\
\hline
\end{tabular}

All specimens from the same batch were placed over a calibrated table underneath the area of action of the robot. A surface pass of the tool was performed before milling the first batch specimens to verify the virtually pre-programmed toolpaths with the actual circumstance. With the spindle motor 
turned off, the milling tool was carefully positioned at different points close to the top surface within the area to be milled; then positions of all the first batch specimens were fixed with wood bars and nails on the table as a benchmark for specimens of the rest two batches to ensure constant and precise cutting positions across all the three batches. Milling took place from Set 1 (fixed spindle speed, variable feed rates) to Set 2 (fixed feed rates, variable spindle speed). Figure 6 shows the production of the samples during (a) and after milling (b). After milling, specimens were left to cure under for 5 days, when they were visually inspected and transported to the Metrology Laboratory for characterisation of the surface finish.
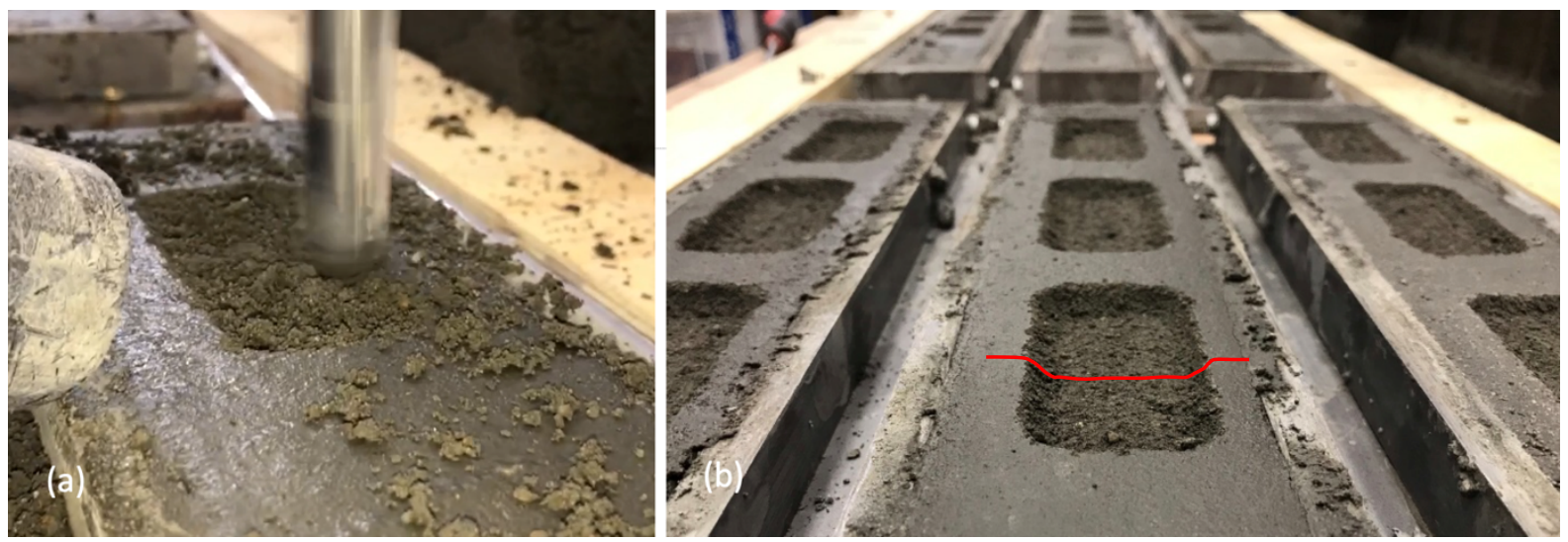

Figure 6: Image taken during milling one region (a) and a batch of milled specimens where the red line indicates the profile of the milled area (b).

\subsection{Measuring material set rate}

The assessment of the mortar setting process was performed in an automatic Vicat penetration apparatus (Vicatronic Automatic Computerised VICAT Recording Apparatus) according to the experimental procedure defined in BS EN 196-3 [43]. For the purpose of defining when to mill, the setting start time was considered the earliest moment the Vicat needle penetrates $35 \mathrm{~mm}$ or less in the mortar sample. Conversely, the setting end time was considered as the earliest moment the Vicat needle penetrations $1 \mathrm{~mm}$ or less in the sample. The authors carried out the tests to mimic the curing conditions of 3D printed samples in their labs; printed parts in their labs are immediately slightly sprayed with water and covered with damped hessian and covered with plastics sheets.

\subsection{Measurement of surface quality}

The surface finish of machined samples was measured using two instruments, a Talysurf $2000 \mathrm{CLI}$ and an Alicona Infinite Focus system: the latter is a light-based system that uses variable focus to determine depth and was used to image the texture of the machined concrete surfaces for visual inspection; and the former uses laser triangulation to measure surface profiles spanning the full width of machined samples. From these profiles the cross-sectional form of the machined section can be determined (see the red line on Figure $6 \mathrm{~b}$ ) and from the profile data it is also possible to extract surface parameters useful to characterise the quality of the machined surface finish. 
323 The parameter evaluated in this work was $\mathrm{Pa}$ and $\mathrm{Pz}$. Both are calculated from the levelled but 324 unfiltered primary profile extracted from the 'flat' bottom of the milled test pockets indicated by the 325 red line in Figure 6b. Pa gives an arithmetic mean based on the integration, over the full length of the profile extracted from the bottom of the milled pocket, of the magnitude of deviation from a best fit centre line. $P z$ is a maximum peak to valley displacement measurement of the surface profile. The instrument was set to sample points at a resolution of $3 \mu \mathrm{m}$ using a laser gauge. Because the system uses optical measurements, some missing point data can occur due to light produced by the laser to be reflected, or diffracted away from the optical sensor and so a gaussian filter was applied to the data to remove these erroneous measurements. However, these occurred infrequently in the samples collected in this work and do not influence the results to any significant degree.

\section{Results}

\subsection{Material state}

Figure 6 below show the average Vicat results for the concrete mix used. The purple, the green and blue lines are the penetration of the Vicat needle over time, the initial and final setting times respectively. The transparent green rectangles represent the milling periods used in the study, at approximately 3.5, 5.9 and 7 hours: the plastic, semi-plastic and solid phases of concrete setting [44]. These correspond to 0.66 of the initial set, during the setting, and 1.11 of the final set, respectively. The first milling time ( 3.5 hours) occurred during the dormant/induction period of the concrete, the second milling ( 5.9 hours) occurred during the transition stage (from plastic to solid-state), and the third milling time ( 7 hours) correspond to the solid-state phase. It should be noted that the 7-hour milling time is chosen to be close to the final set when the stiffness of concrete still allows for it to be machined.

The Vicat was used to precisely determine the starting of milling time for each milled section on each sample to ensure that the condition of the concrete was similar across time replicate samples. Practically, this led to a milling time 'window' shown by the green bars in Figure 7 across the samples taken, rather than a single predefined time from the onset of hydration. 


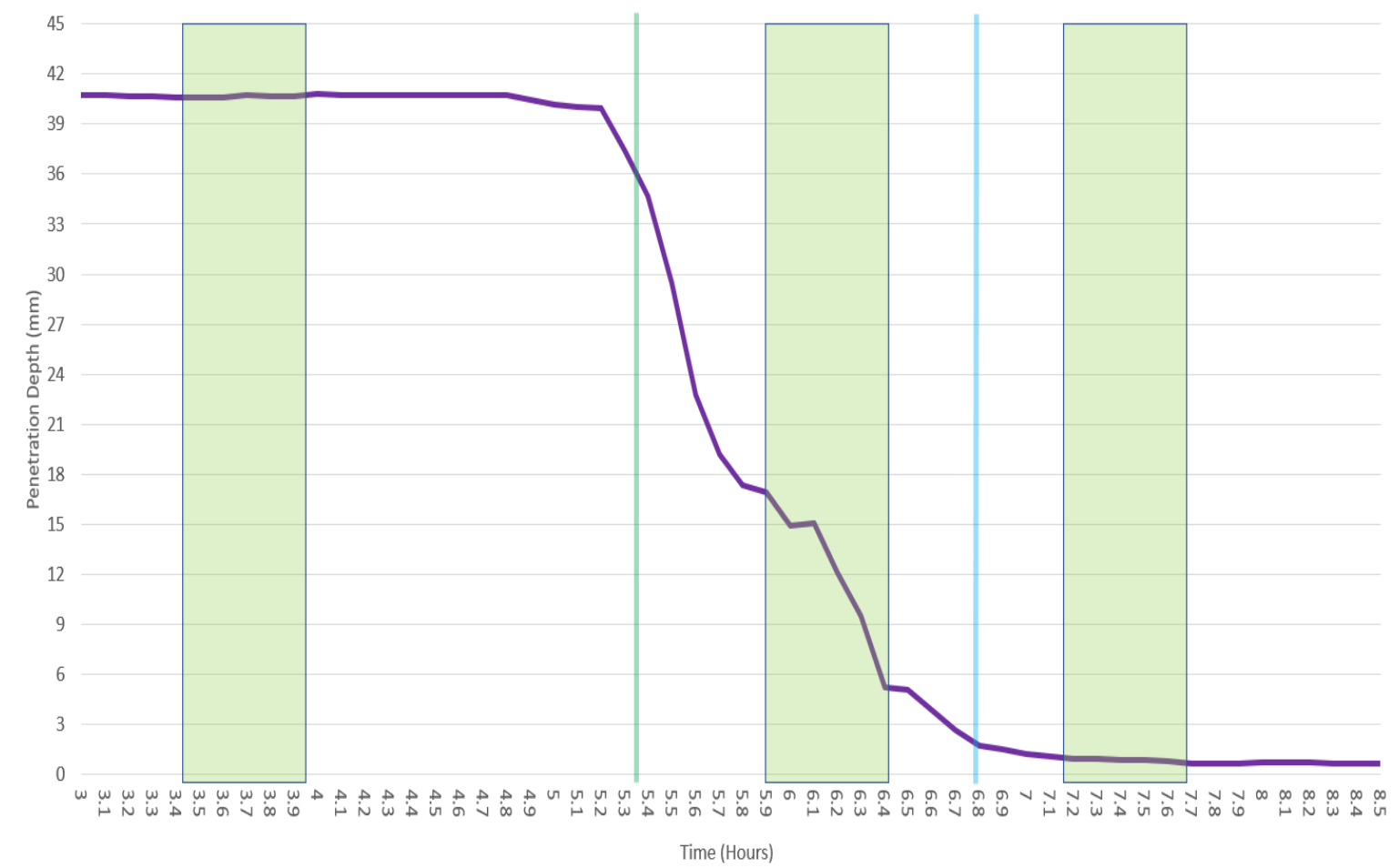

Figure 7: Penetration depth measured by the Vicat for the mortar used in the experiments.

\subsection{Profile inspection}

From the milled pocket samples depicted in Figure $6 \mathrm{~b}$, three profile measurements were collected from three regions with approximately $10 \mathrm{~mm}$ spacing between the profiles. Figure 8 presents three profile measurements that illustrate the general observations made regarding the curing state of the material.

In order to visually communicate the expected profile, Figure $8 \mathrm{c}$ depicts the notional outline of the tip of the end-mill shaded in green and what might be the expected finished milled profile surface by the dashed green line. The tool path configuration employed here was a continuous spiral that started in the centre of the part and worked outwards, resulting in the tip of the tool cutting into every part of the surface. Figure 6 a illustrates the size of the $16 \mathrm{~mm}$ diameter end-mill tool in relation for the sample surface. In Figure $8 \mathrm{c}$ one can visualise the tool position illustrated would be on the outermost cut, moving into, or out of the page.

Figure $8 a$ is taken from the sample at 3.5 hours (plastic state), with a cutting speed of $45 \mathrm{~mm} / \mathrm{s}$. The best-case results show $P z$ (peak to valley) results of $4.1 \mathrm{~mm}$ and a $P a$ (mean) of $0.8 \mathrm{~mm}$. While the mean surface might appear small, there is a distinct lack of material removal in the centre of the profile with the tooling channels visible toward the edges of the samples. This is caused by two factors: one the soft state of the material makes it quite 'sticky' when it is milled and well-defined chips are not formed during cutting. In fact, it was observed that the material remained on the surface and was pushed around by the tool. The outward spiral toolpath resulted in the material being pushed towards the centre, and consolidated to an extent, resulting in the observed profile. 
In Figure $8 \mathrm{~b}$ the material was cured for 5.9 hours and in plastic-solid state. The formation of the profile is greatly improved with $P z$ between 0.8 and $1.4 \mathrm{~mm}$ and an $P a$ of 0.3 to $0.18 \mathrm{~mm}$ and in Figure $8 \mathrm{c}$ similar results when the material in in its solid-state phase at 7 hours. There were marginal differences in the quality of the surfaces between these two material states, with marginally better definition in the solid-state sample. However, the differences were small. The principle observation was during the milling when the tool 'chatter' was quite evident when milling the harder sample. This is due to the deflection of the tool as it tries to cut into the surface. It is dependent on many factors including the type of cutter, length of the tool, stiffness of the tool and positioning devices. This highlighted the value of completing milling while the material is sufficiently compliant when using light weight positing devices and versatile (and inexpensive) tools.

\section{Trowelled flat top of cast sample}
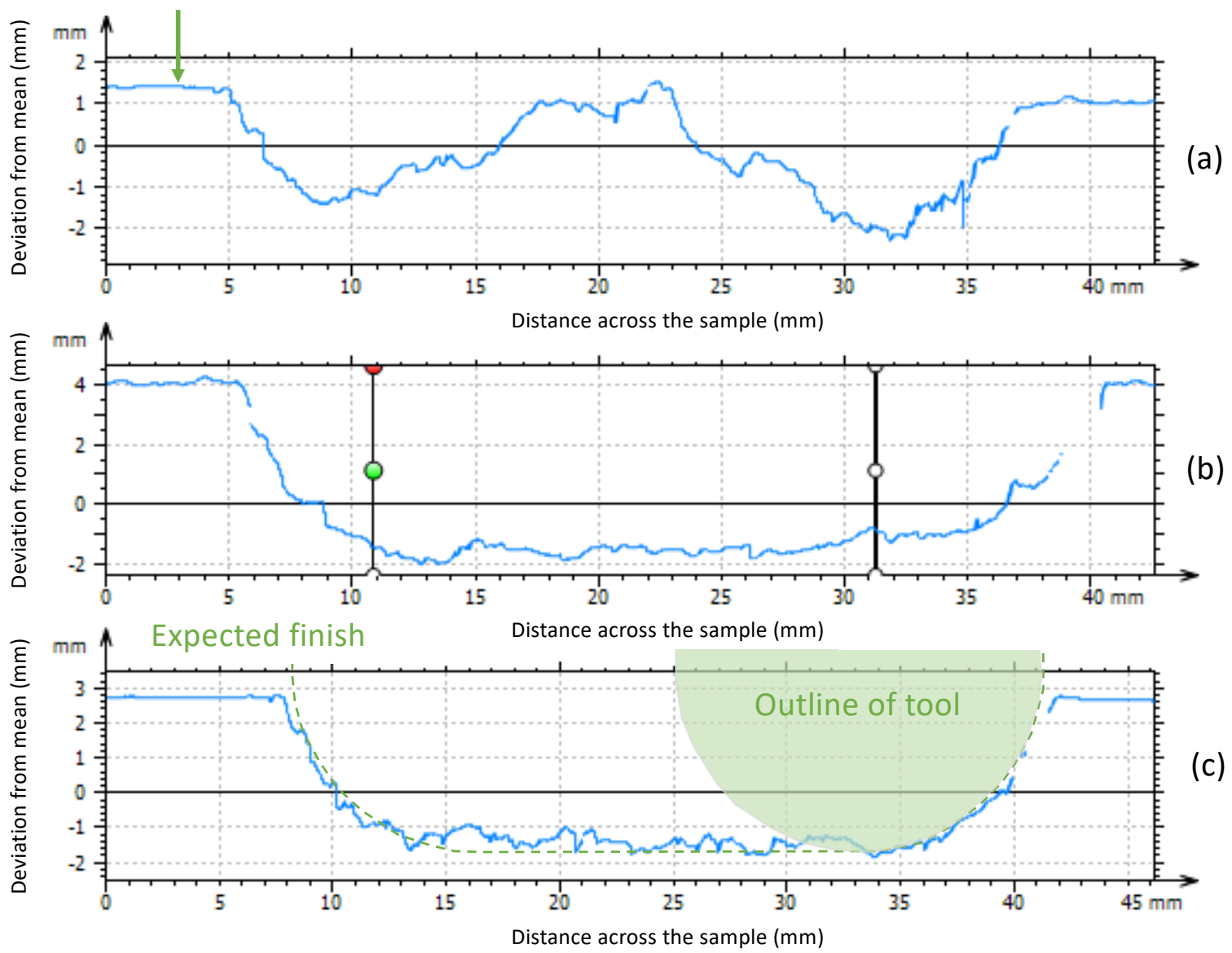

Figure 8: three sample profiles from the investigation: (a) in the plastic state, (b) in the transition from plastic to solid state, and (c) in the solid state. The notional outline of the milling trough and the end mill is shown in (c) to approximate scale.

\subsection{Visual surface inspection}

Figure 9 presents four images taken using the Alicona which are approximately $25 \mathrm{~mm}$ by $40 \mathrm{~mm}$ in size, measured with a lateral sampling resolution of $20 \mu \mathrm{m}$. These are colour photographic images of the natural colour of the mortar that have been enhanced with a colour scale to improve the visual 

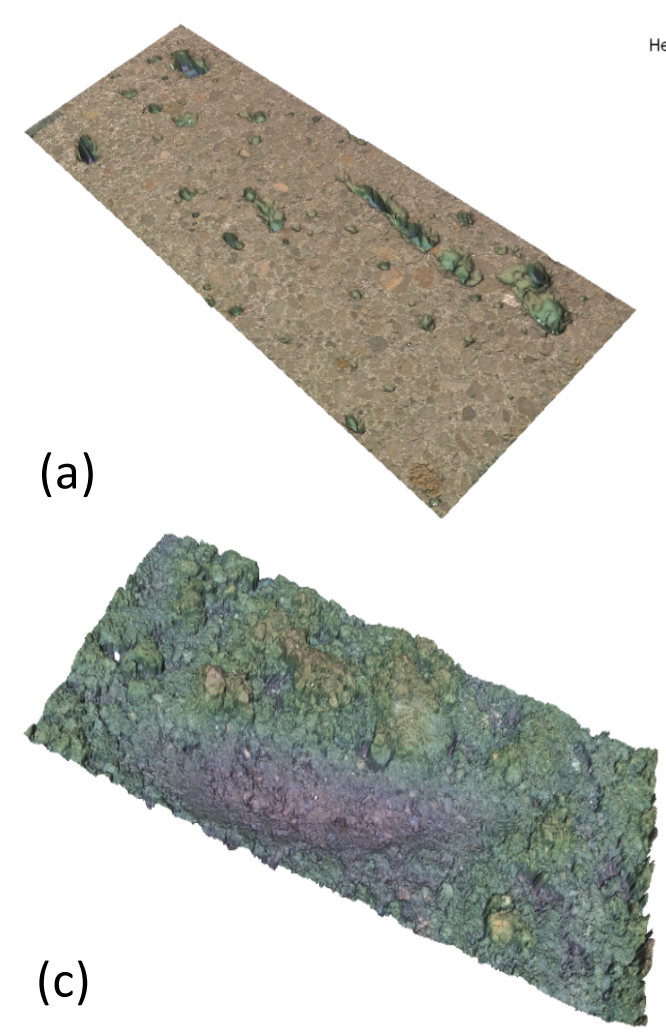

Figure 9a presents the measurement technique applied to a polished surface of 3D concrete printed mortar, of the same mix design as the samples used in this investigation as a reference. The majority of the ground surface is perfectly flat, but the measurement technique is sensitive enough to expose areas where harder aggregates have been pulled out, or air bubbles in the mix have been exposed.

Figure $9 \mathrm{~b}$ shows part of a milled surface where a larger piece of aggregate has been exposed and pushed in the milling direction with a large valley formed behind it. Conversely Figure 9c showed a gouge where the cutter has made a deeper cut, most likely is that a piece of aggregate has been pulled out of the material by the tool. Figure $9 \mathrm{~d}$ shows the cut profile made by the ball-nose of the tool.

These images evidence a key observation: that the resultant surface produced by milling mortars in this plastic state will not only be influenced by the configuration of the tooling (cut depths, speeds, stepover etc.) but also inherent nature of the composite material. The size of aggregates used will directly influence the surface quality through displacement and pull-out mechanisms. Subtractive or finishing processes applied to the hardened material rely on the strength of the matrix material to hold aggregate in place, forcing the tool to cut through the aggregate.
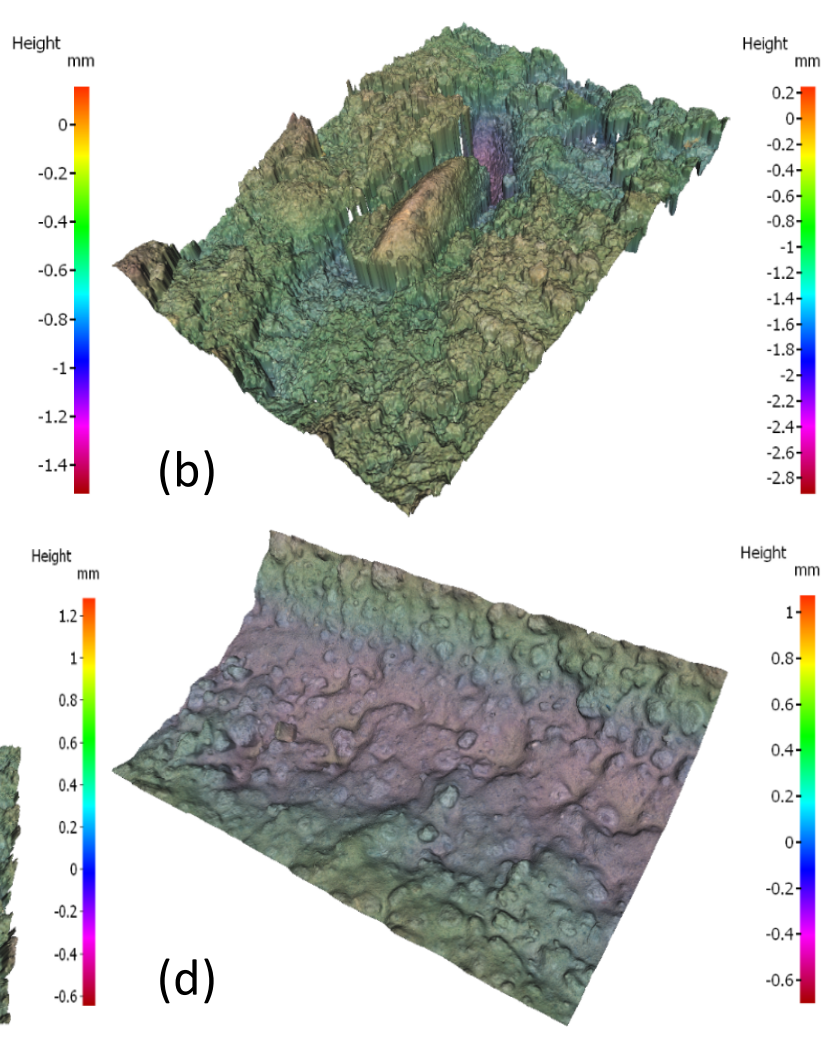

Figure 9: colour enhanced photographic images of surfaces of mortar at 10 magnification: (a) a reference polished concrete surface; (b) a piece of aggregate that has been pushed into the sample by the tool; (c) a gouge made by the tool; (d) the cutting profile made by the bull-nose tool. 
Figure 10 shows the measured surface roughness of the milled samples. With the material in its plastic state ( 3.5 hours) the $P a$ (average surface roughness) value can be as high as $1.5 \mathrm{~mm}$ with a feed rate of $15 \mathrm{~mm} / \mathrm{s}$ (Figure 10a). As commented in the previous section, the material appears to be relocated with the sample, rather than removed from it, but at higher speeds the $P a$ decreases to $0.8 \mathrm{~mm}$ at a traversal speed of $45 \mathrm{~mm} / \mathrm{s}$. It is likely that the higher energy input to the system assists in throwing the material clear of the milled surface, however at $90 \mathrm{~mm} / \mathrm{s}$ the material removal rate slows and the $\mathrm{Pa}$ measurement shows no discernible increase. Why this is the case is unclear but it may be related to the milling edge moving through the material too quickly to effectively produce chips to remove the material and/or clogging of the mill flutes which will reduce the cutting effectiveness of the tool.

(a)

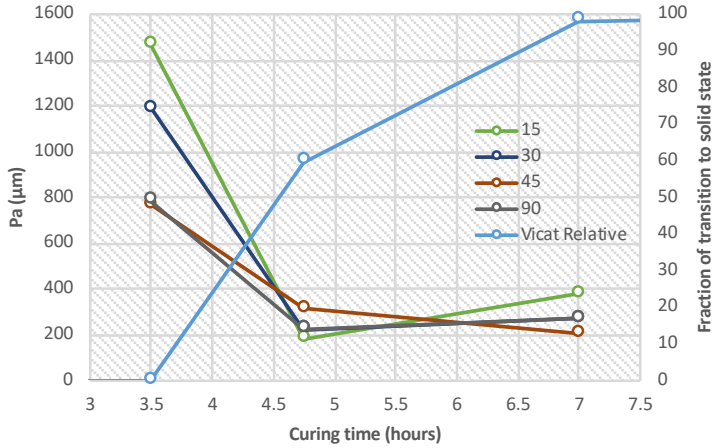

(c)

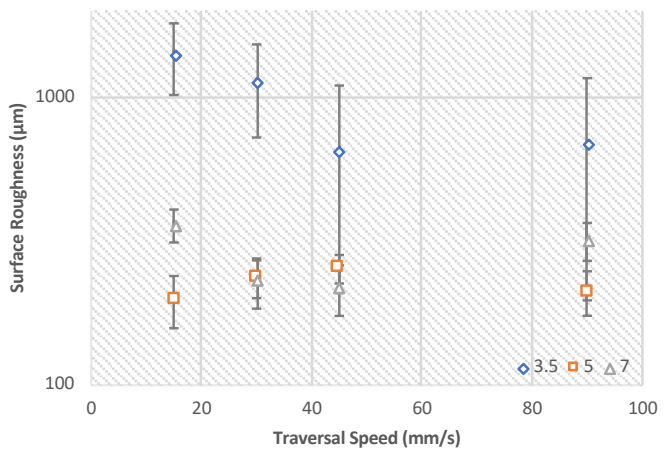

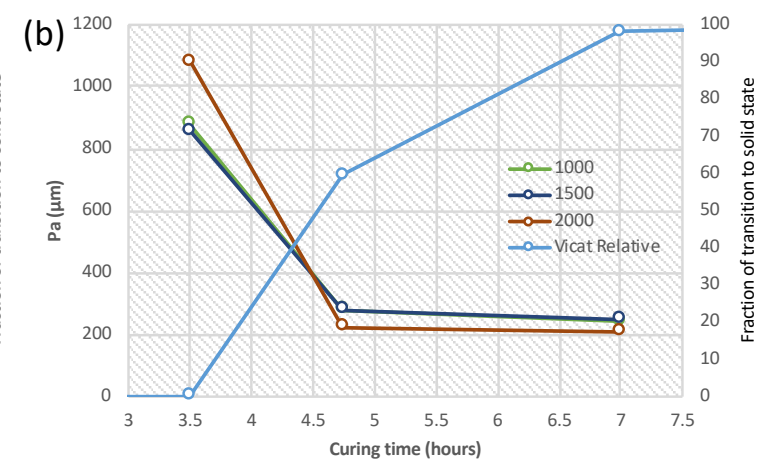

(d)

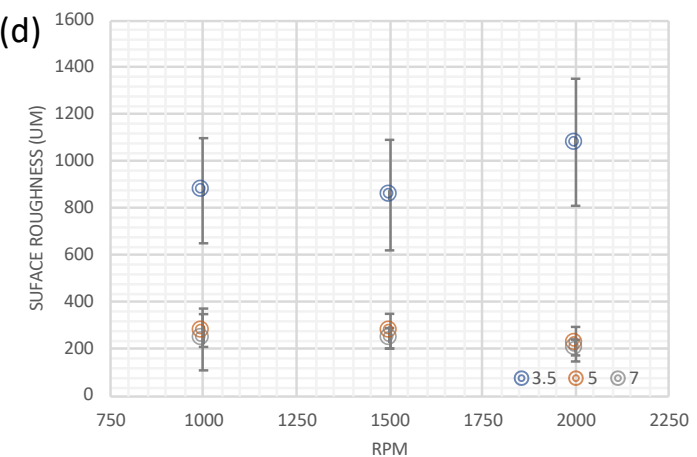

Figure 10: dependency of surface roughness as a function of material state for cutting speed (a), and tool rotational speed (b) and surface roughness as a function of cutting speed (c) and tool rotational speed (d) for the three material states.

The observed standard deviations in the surface roughness are larger for the 3.5 hours samples, for the reasons previously discussed as seen in Figure 10c. The results become more repeatable as the material transistions to its solid state. Also usig a higher tool rotational speed improves the surface (Figure $10 \mathrm{~d}$ ): $0.22 \mathrm{~mm}$ at a spindle speed of $2000 \mathrm{rpm}$ vs $0.28 \mathrm{~mm}$ at spindle speeds of $1500 \mathrm{rpm}$ and 1000 rpm. However, it is evident that given the variation in the samples, the dominant factor is the material state, producing significantly results for surface finish as it is transitioning to its solid state.

During climb and conventional milling process cuts were taken at D/2, D/4 and D/6 of the cutter diameter. Climb milling showed more consistent results for both curing and post cured phases with a variation of only $18 \mu \mathrm{m}$ at the different cutting depths in the curing phase. The grouping of the shallower cuts shows large consistency across all of the curing times. Climb milling is generally used in materials processing to achieve better surface finishes, as the material cures climb milling shows better results for the surface finish of the material even with larger cut depths. The results for both climb and conventional milling can be seen in Figure 11. Axial cuts are taken down the axis of rotation of the tool, these show high consistency during the transition phase with a variation of $28 \mu \mathrm{m}$ on the 
different cutting depths. With larger axial cuts material is forced up the flutes of the cutter and removed from the milled area. When the material was uncured the material is pushed around and not completely expelled at lower cut depths. This is possibly due to the ball nosed profile of the tool. Once cured at the lowest cut depth chatter was heard during the cutting phase as the tool skipped across the surface of the milled surface. As with the previous hypothesis this is most likely due to the tool geometry. Axial cut surface roughness may be viewed in Figure 11c.
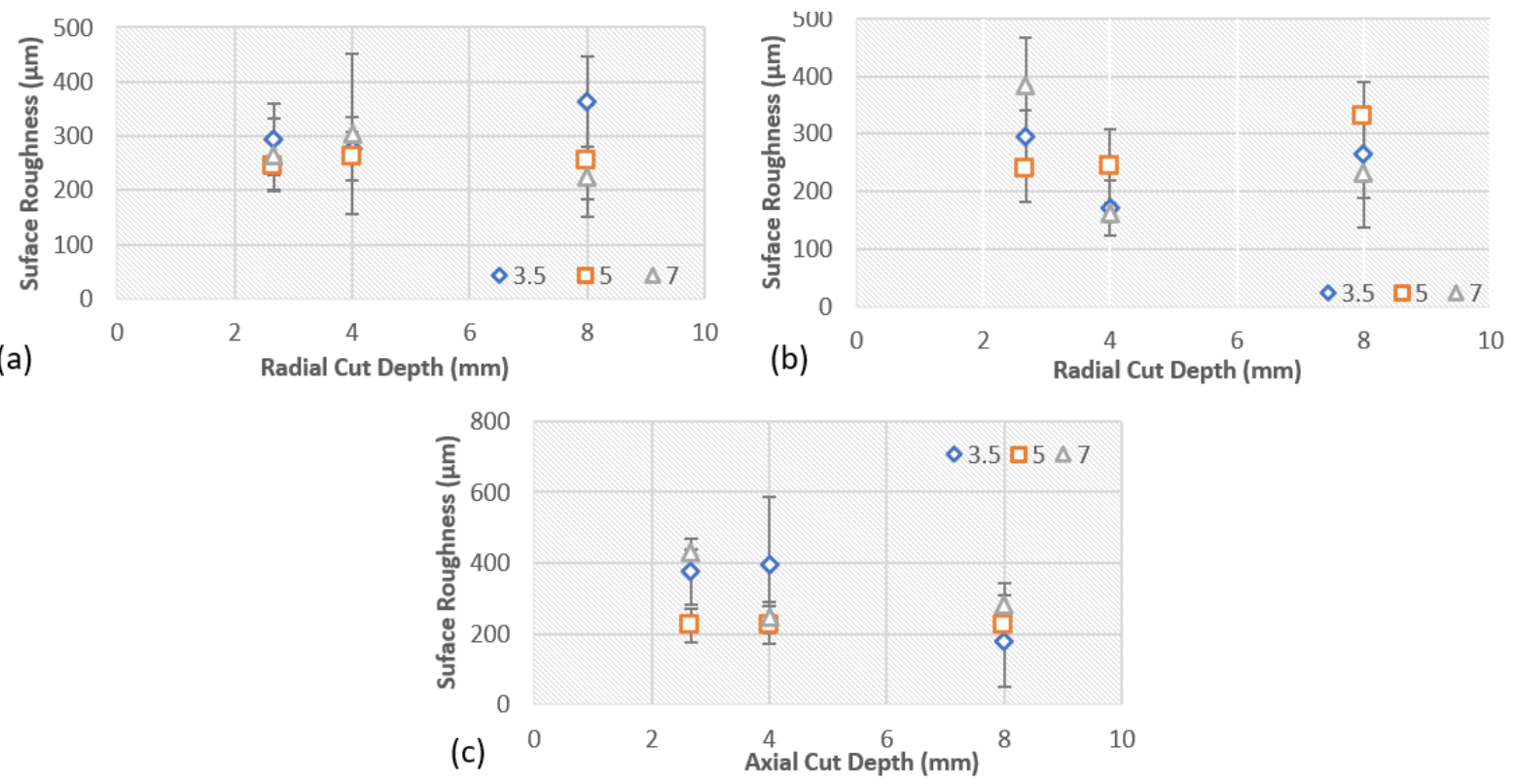

Figure 11: dependency of surface roughness as a function of material state for climb milling (a), and conventional milling (b), Axial cut depths are shown (c)

Milling can be carried out when the material is in its plastic state, but the material is displaced rather than removed and resultants in a poor-quality milled surface. Although there were no details published in this regard by Lindemann et al. [35] and Kloft et al. [36], it is likely that rotational trowelling approach in their finishing process utilised the material close to this state.

Milling is effective as the material transitions to its solid state, although the surface quality appears to be less sensitive to tool speeds than for typical materials that are milled. In addition, the abrasive nature of the material may not correlate well with existing studies such as that by Sredanović et al. [33] to minimise tool wear.

The optimal results found by this study were when the material transitioned to, or was just in its solid state. Given the standard deviations calculated from the measurements, there were insignificant differences between the different tooling parameters. Typically, in machining metals and other materials there is an optimal arrangement of these, but these are typically homogeneous and/or are in a solid state. The action of cutting it is therefore dependent on the forces and trajectories of the cutting action balanced with the speeds of materials and tool [45]. 
days or more. The compressive strength of this mix at the time of milling in its plastic-solid state compared well to similar work of others $(19-35 \mathrm{kPa})[23,46]$, whereas the reported compressive strength of the mix once fully cured is $100 \mathrm{MPa}$ [41].

This will mean that once the material is hard enough to form chips during milling, and not clog the flutes of the tool it will mill the matrix quite well, but the ability of the material to deform under the forces applied is still present and this will lead to the displacement of the aggregates in the matrix, or result in pull-out occurring, leaving a hole behind. This is potentially undesirable as it will limit the surface type that is achievable with a mill tool, but it will depend on the specification of the surface, we should not forget that the data gathered here is measured over $25 \mathrm{~mm}$ sample profiles, and we are drawing conclusions based on data where the differences are in the order of $0.25 \mathrm{~mm}$.

To provide some context to the roughness of the milled surface as it compares to other common surface preparations, the Talysurf was applied to this mix design and the polished surface depicted in Figure $8 a$, the trowelled surface indicated in Figure $6 b$ from the top of the mould on the test samples and the underside of the samples that were cast against a standard steel mould depicted in Figure 4. The data in Table 4 shows that the hand applied floated finish is twice as rough as the cast surfaces and is representative of surfaces the level of surface finish achievable in steel moulds. The milled surfaces are an order of magnitude rougher that these traditional treatments, however notwithstanding this, it is a precisely formed flat surface and represents an alternative surface finish conventional casting. Importantly, from an experimental perspective, a measurement of a milledprinted and a milled-cast surface yields a very small difference that is well within the measurement. error in these samples.

Table 4: surface types and roughness measurements on the 3D concrete printing mortar with a maximum aggregate size of $2 \mathrm{~mm}$.

\begin{tabular}{lc}
\hline Surface & $\mathrm{Pa}(\mathrm{mm})$ \\
\hline Polished & 0.015 \\
Cast on steel mould & 0.015 \\
Floated & 0.029 \\
Milled Cast Material & 0.250 \\
Milled Printed Material & 0.255 \\
\hline
\end{tabular}

In combination with the additive shaping process and robotic tool positioning surfaces created using the ball-nosed cutter can be reproduced at any angle or position on a part where there is tooling access and where the strength of the part can sustain the forces during milling. An advantage of using this type of tool means that quite small areas and details can be treated.

\section{Limitations, further work and outlook}

As the mill cuts the material there is the potential to expose voids, either within the filament, between filaments, or between layers such as those reported in $[39,40]$. Neither the samples or the initial 3DCP trials reported here exhibited the latter two cases because the material is very well consolidated, and practically fully-dense. The results showed no evidence that the small $(>1 \mathrm{~mm})$ pores in the filament influenced the roughness of the milled surface.

There are two, or potentially three factors that could influence this. The first is the relative size of the pore in relation to the size of the aggregate. The majority of voids here were less that $1 \mathrm{~mm}$ which is 
of the same order of the tooling marks depicted in Figure 9. The effect of pore size on the results is therefore likely to be small, and in addition, the smaller pore sizes in the printed samples would influence the result even less. Material composition is likely to be an important factor and further work is needed to characterise these effects.

The surface orientation may also be a factor in final surface roughness. The horizontal surfaces examined here are prone to milled chippings naturally falling on to the surface and require extraction by some means. This may influence the final flatness measurements, possibly 'filling in' some exposed pores, which may not happen on vertical surfaces, but further work is need to explore this phenomenon.

Thirdly, the curing approach adopted here where printed components are not exposed to ambient conditions is part of the standard production procedure at Loughborough, where the application of the technology to manufactured components is investigated. Surface drying of exposed parts and the use of admixtures to control the set is likely to modify the stage at which optimal milling takes place, and may well influence the chip formation. The milling of a material with time variant properties is still a very new concept in all fields of manufacturing and these questions will undoubtedly form the basis for further investigations. This study offers a systematic approach that can be adapted in future work.

The ability to efficiently mill concrete before it is solid has advantages in allowing the use of lighter weight robotic arms commonly used in 3DCP applications. However, one of the limiting factors in this work was in fact was the rigidity of the machine as the material approached its solid state. The tool noise created as it chattered on the surface during milling was audible, and so clearly the timing of such treatments is critical and will become more relevant as the milling area increases. Additionally, this relates to the ability of the matrix to hold the aggregates, which are prone to pull-out and displacement of the larger aggregates used. Trowelling surfaces when the material is more compliant $[35,36]$ will have advantages for certain applications. Further work is needed to explore the extent of this 'milling window' and the use of control through admixtures to determine the implications and challenges for milling larger areas of material.

A final observation is that hybrid approaches that use subtractive machining need to minimise the waste material that is generated and this will be achieved by a combination of well controlled printing, and optimised tool paths through design for manufacture principles. However, the work presented in [34] is encouraging in that it demonstrates the sustainability benefits of hybrid approaches over cast equivalents for low volume production.

\section{Conclusions}

To the best knowledge of the authors, this study represents the seminal investigation into the influence of the transition of cement-based mortar from its plastic to solid state on the surface roughness achieved through a milling process. It introduced a new testing procedure to the rapidly developing field of Digital Fabrication with Concrete and demonstrated the feasibility of milling concrete in its green-state.

Potential applications exist in conventional cast material, but in particular for the use in combination with additive processes where surface of printed components may be treated to increase the smoothness of the printed surfaces, or to correct any deformations that might occur during printing. 
The work demonstrated that milling green material can produce repeatable, flat surfaces with a roughness of $0.25 \mathrm{~mm}$, which compares to $0.015 \mathrm{~mm}$ for surfaces cast against steel moulds and as such presents a different surface finish to traditional methods. The surface finish was not particularly sensitive to tooling parameters such as feed and speed rates but is was sensitive to material state, requiring it to be approaching the solid state but remaining compliant enough to be cut. Once the solid state it reached, the 'lighter weight' robotic arms commonly used for 3DCP struggle to accidently apply the tool with the forces needed to cut the material and hence the 'milling window' becomes a critical parameter to establish for hybrid systems.

Finally, because the milled material is a composite comprising of harder aggregates ( $\max 2 \mathrm{~mm}$ in the work) held in a more compliant matrix, the displacement and pull out of these will affect the resultant surface condition and hence mix formulation and maximum aggregate size will be an important consideration for those applications where hybrid manufacturing approaches might be adopted.

\section{Acknowledgements}

This work was supported by UKRI grant award numbers EP/S031405/1 and EP/S019618/1.

\section{References}

[1] HMGov, Modern methods of construction, London, 2019. https://publications.parliament.uk/pa/cm201719/cmselect/cmcomloc/1831/183102.htm (accessed May 24, 2021).

[2] F. Barbosa, J. Woetzel, J. Mischke, M.J. Ribeirinho, M. Sridhar, M. Parsons, N. Bertram, S. Brown, Reinventing construction through a productivity revolution | McKinsey, 2017. https://www.mckinsey.com/business-functions/operations/our-insights/reinventingconstruction-through-a-productivity-revolution\# (accessed May 24, 2021).

[3] G. Siemens, Connectivism: A Learning Theory for the Digital Age, Int. J. Instr. Technol. Distance Learn. 2 (2004).

[4] B. Khoshnevis, D. Hwang, K.T. Yao, Z. Yeh, Mega-scale fabrication by Contour Crafting, Int. J. Ind. Syst. Eng. 1 (2006) 301-320. https://doi.org/10.1504/IJISE.2006.009791.

[5] S. Lim, R.A. Buswell, T.T. Le, S.A. Austin, A.G.F. Gibb, T. Thorpe, Developments in constructionscale additive manufacturing processes, Autom. Constr. 21 (2012) 262-268. https://doi.org/10.1016/j.autcon.2011.06.010.

[6] N. Labonnote, A. Rønnquist, B. Manum, P. Rüther, Additive construction: State-of-the-art, challenges and opportunities, Autom. Constr. 72 (2016) 347-366. https://doi.org/10.1016/j.autcon.2016.08.026.

[7] R.A. Buswell, W.R. Leal de Silva, S.Z. Jones, J. Dirrenberger, 3D printing using concrete extrusion: A roadmap for research, Cem. Concr. Res. 112 (2018) 37-49. https://doi.org/10.1016/j.cemconres.2018.05.006.

[8] T. Wangler, N. Roussel, F.P. Bos, T.A.M. Salet, R.J. Flatt, Digital Concrete: A Review, Cem. Concr. Res. 123 (2019) 105780. https://doi.org/10.1016/j.cemconres.2019.105780.

[9] M.S. Khan, F. Sanchez, H. Zhou, 3-D printing of concrete: Beyond horizons, Cem. Concr. Res. 133 (2020) 106070. https://doi.org/10.1016/j.cemconres.2020.106070.

[10] R.A. Buswell, W.R.L. da Silva, F.P. Bos, H.R. Schipper, D. Lowke, N. Hack, H. Kloft, V. Mechtcherine, T. Wangler, N. Roussel, A process classification framework for defining and describing Digital Fabrication with Concrete, Cem. Concr. Res. 134 (2020) 106068. https://doi.org/10.1016/j.cemconres.2020.106068. 
[11] I. Gibson, D. Rosen, B. Stucker, Additive Manufacturing Technologies - 3D Printing, Rapid Prototyping, and Direct Digital Manufacturing, 1st ed., Springer New York, (2015). https://doi.org/10.1007/978-1-4939-2113-3_1.

[12] R. Hague, I. Campbell, P. Dickens, Implications on design of rapid manufacturing, Proc. Inst. Mech. Eng. Part C J. Mech. Eng. Sci. 217 (2003) 25-30. https://doi.org/10.1243/095440603762554587.

[13] Y.Y. Ling, K.C. Leo, Reusing timber formwork: Importance of workmen's efficiency and attitude, Build. Environ. 35 (2000) 135-143. https://doi.org/10.1016/S0360-1323(99)00008-6.

[14] BS EN 1992-1-1, Eurocode 2: Design of concrete structures. General rules and rules for buildings, London, 2014.

[15] BS EN 13369, Common rules for precast concrete products, London, 2018.

[16] BS 8297, Design, manufacture and installation of architectural precast concrete cladding. Code of practice, London, 2017.

[17] M.K. Hurd, Formwork for concrete, American Concrete Institute, Farmington Hills Mich, 2005.

[18] A. Jipa, M. Bernhard, M. Meibodi, B. Dillenburger, 3D-Printed Stay-in-Place Formwork for Topologically Optimized Concrete Slabs, in: Proc. 2016 TxA Emerg. Des. + Technol. Conf., Texas Society of Architects, (2016) 97-107. https://doi.org/10.3929/ethz-b-000237082.

[19] W.J. Hawkins, M. Herrmann, T.J. Ibell, B. Kromoser, A. Michaelski, J.J. Orr, R. Pedreschi, A. Pronk, H.R. Schipper, P. Shepherd, D. Veenendaal, R. Wansdronk, M. West, Flexible formwork technologies - a state of the art review, Struct. Concr. 17 (2016) 911-935. https://doi.org/10.1002/suco.201600117.

[20] S. Maitenaz, R. Mesnil, P. Onfroy, N. Metge, J.F. Caron, Sustainable Reinforced Concrete Beams: Mechanical Optimisation and 3D-Printed Formwork, in: RILEM Bookseries, Springer, (2020) 1164-1173. https://doi.org/10.1007/978-3-030-49916-7_110.

[21] M. Bekaert, K. Van Tittelboom, G. De Schutter, Printed Concrete as Formwork Material: A Preliminary Study, in: RILEM Bookseries, Springer, (2020) 575-583. https://doi.org/10.1007/978-3-030-49916-7_59.

[22] A. Perrot, D. Rangeard, A. Pierre, Structural built-up of cement-based materials used for 3Dprinting extrusion techniques, Mater. Struct. Constr. 49 (2016) 1213-1220. https://doi.org/10.1617/s11527-015-0571-0.

[23] R.J.M. Wolfs, F.P. Bos, T.A.M. Salet, Early age mechanical behaviour of 3D printed concrete: Numerical modelling and experimental testing, Cem. Concr. Res. 106 (2018) 103-116. https://doi.org/10.1016/j.cemconres.2018.02.001.

[24] L. Reiter, T. Wangler, N. Roussel, R.J. Flatt, The role of early age structural build-up in digital fabrication with concrete, Cem. Concr. Res. 112 (2018) 86-95. https://doi.org/10.1016/j.cemconres.2018.05.011.

[25] A.S.J. Suiker, R.J.M. Wolfs, S.M. Lucas, T.A.M. Salet, Elastic buckling and plastic collapse during 3D concrete printing, Cem. Concr. Res. 135 (2020) 106016. https://doi.org/10.1016/j.cemconres.2020.106016.

[26] S. Lim, R.A. Buswell, P.J. Valentine, D. Piker, S.A. Austin, X. De Kestelier, Modelling curvedlayered printing paths for fabricating large-scale construction components, Addit. Manuf. 12 (2016) 216-230. https://doi.org/10.1016/j.addma.2016.06.004.

[27] W. Hong, Y.T. Lee, H. Gong, A study of the staircase effect induced by material shrinkage in $\begin{array}{llllll}\text { rapid prototyping, Rapid Prototyp. J. } 11 & \text { (2005) 82-89. }\end{array}$ https://doi.org/10.1108/13552540510589449. 
[28] J. Xu, R.A. Buswell, P. Kinnell, I. Biro, J. Hodgson, N. Konstantinidis, L. Ding, Inspecting manufacturing precision of 3D printed concrete parts based on geometric dimensioning and $\begin{array}{lllll}\text { tolerancing, } & \text { Autom. } & \text { Constr. } & 117 & \text { (2020) }\end{array}$ https://doi.org/10.1016/j.autcon.2020.103233.

[29] I.E. UhImann, M. Manthei, Analysis of the cutting process for milling of marble and sandstone with an end mill cutter, in: International Conference on Stone and Concrete Machining (ICSCM), (2015) 54-60. https://doi.org/10.13154/ICSCM.3.2015.54-60.

[30] B. Denkena, T. Grove, U. Hess, A new method for the local removal of the surface area of reinforced concrete, in: International Conference on Stone and Concrete Machining (ICSCM), (2015) 43-53. https://doi.org/10.13154/ICSCM.3.2015.43-53.

[31] N. Kepczak, P. Zgorniak, P. Lajmert, R. Rosik, M. Sikora, Influence of machining parameters on the polymer concrete milling process, Int. J. Adv. Manuf. Technol. 106 (2020) 3017-3032. https://doi.org/10.1007/s00170-019-04811-x.

[32] J. Hayes, S. Fai, S. Kretz, C. Ouimet, P. White, Digitally-Assisted Stone Carving of a Relief Sculpture for the Parliament Buildings National Historic Site of Canada, ISPRS Ann. Photogramm. Remote Sens. Spat. Inf. Sci. II-5/W3 (2015) 97-103. https://doi.org/10.5194/isprsannals-II-5-W3-97-2015.

[33] B. Sredanovic, G. Globocki Lakic, D. Kramar, F. Pušavec, Influence of Workpiece Hardness on Tool Wear in Profile Micro-milling of Hardened Tool Steel, Tribol. Ind. 40 (2018) 100-107. https://doi.org/10.24874/ti.2018.40.01.09.

[34] Muñoz, I., Alonso-Madrid, J., Menéndez-Muñiz, M. et al. Life cycle assessment of integrated additive-subtractive concrete 3D printing. Int J Adv Manuf Technol 112, 2149-2159 (2021). https://doi.org/10.1007/s00170-020-06487-0

[35] H. Lindemann, R. Gerbers, S. Ibrahim, F. Dietrich, E. Herrmann, K. Dröder, A. Raatz, H. Kloft, Development of a shotcrete 3D-printing (SC3DP) technology for additive manufacturing of reinforced freeform concrete structures, in: RILEM Bookseries, Springer Netherlands (2019) 287-298. https://doi.org/10.1007/978-3-319-99519-9_27.

[36] H. Kloft, N. Hack, J. Mainka, D. Lowke, Large Scale 3D Concrete Printing: Basic Priciples Of 3D Concrete Printing, CPT Worldw. Constr. Print. Technol. 1 (2019) 28-35.

[37] J. Bard, D. Cupkova, N. Washburn, G. Zeglin, Robotic concrete surface finishing: a moldless approach to creating thermally tuned surface geometry for architectural building components using Profile-3D-Printing, Constr. Robot. 2 (2018) 53-65. https://doi.org/10.1007/s41693-0180014-x.

[38] Manuel Menendez Muñiz, Marjorie Chantin, Cristian Raul Vintila, Marc Fabritius, Christoph Martin, Laura Calvo, Louison Poudelet, Joseph Canou, Maylis Uhart, Alexios Papacharalampopoulos, Panos Stavropoulos, Nils Olof Emanuel Olsson, José Antonio Tenorio, Javier Alonso Madrid, Justin Dirrenberger, Ivan Muñoz, Concrete hybrid manufacturing: A machine architecture, Procedia CIRP, Volume 97, 2021, Pages 51-58, ISSN 2212-8271, https://doi.org/10.1016/j.procir.2020.07.003.

[39] J. Kruger, A. du Plessis, G. van Zijl, An investigation into the porosity of extrusion-based 3D $\begin{array}{llll}\text { printed concrete, Additive Manufacturing, Volume } 37 & \text { (2021) }\end{array}$ https://doi.org/10.1016/j.addma.2020.101740.

[40] Y. Chen, O. Çopuroğlu, C. Romero Rodriguez, F. F. de Mendonca Filho, E. Schlangen, Characterization of air-void systems in 3D printed cementitious materials using optical image scanning and X-ray computed tomography, Materials Characterization, Volume 173 (2021) https://doi.org/10.1016/i.matchar.2021.110948.

[41] T.T. Le, S.A. Austin, S. Lim, R.A. Buswell, R. Law, A.G.F. Gibb, T. Thorpe, Hardened properties of 
high-performance printing concrete, Cem. Concr. Res. 42 (2012) 558-566. https://doi.org/10.1016/j.cemconres.2011.12.003.

[42] T.T. Le, S.A. Austin, S. Lim, R.A. Buswell, A.G.F. Gibb, T. Thorpe, Mix design and fresh properties for high-performance printing concrete, Mater. Struct. Constr. 45 (2012) 1221-1232. https://doi.org/10.1617/s11527-012-9828-z.

[43] BS EN 196-3, Methods of testing cement. Determination of setting times and soundness, London, 2005.

[44] J.T. Kolawole, R. Combrinck, W.P. Boshoff, Shear rheo-viscoelasticity approach to the plastic cracking of early-age concrete, Cem. Concr. Res. 135 (2020) 106127. https://doi.org/10.1016/j.cemconres.2020.106127.

[45] J.T. Black, E.P. DeGarmo, R.A. Kohse, DeGarmo's Materials and Processes in Manufacturing : J. Temple Black, : 9780470873755 : Blackwell's, John Wiley \& Sons Inc, 2018.

[46] B. Panda, J.H. Lim, M.J. Tan, Mechanical properties and deformation behaviour of early age concrete in the context of digital construction, Compos. Part B Eng. 165 (2019) 563-571. https://doi.org/10.1016/j.compositesb.2019.02.040.

703

704 